Motrivivência Ano XXII, No 34, P. 208-222 Jun./2010

DOI:10.5007/2175-8042.2010n34p208

\title{
OFICINAS PEDAGÓGICAS DE BLOGS NA EDUCAÇÃO FÍSICA: um relato de experiência
}

Lyana Virgínia Thédiga de Miranda?

\begin{abstract}
Resumo
Presente artigo se configura não apenas como um relato de experiência, mas como uma reflexão possibilitada por meio da oficina Incorporação de blogs como ferramenta pedagógica para a Educação Física, ministrada para acadêmicos de Educação Física da Universidade Federal de Santa Catarina (UFSC) e da Universidade Federal de Sergipe (UFS). Com esse relato buscamos colaborar com a sensibilização para a importância de se instituir um diálogo entre Educação Física e cultura digital, partindo de uma perspectiva social, crítica e colaborativa dos meios.

Palavras chaves: Mídia-Educação. Cultura Digital. Blogs
\end{abstract}

\begin{abstract}
This article configures itself not only as an account of the experience, but as a reflection made possible through workshop Embedding blogs as a pedagogical tool for Physical Education, taught physical education for scholars from the Federal University of Santa Catarina (UFSC) and the Federal University of Sergipe (UFS). With this report we collaborate with awareness of the importance of establishing a dialogue between the field of Physical Education and digital culture, starting from a social perspective, critical and collaborative media.

Keywords: Media-Education. Digital Culture. Blogs
\end{abstract}

1 Publicitária, jornalista e acadêmica de Educação Física (UFSC). Bolsista PIBIC / CNPq / UFSC e integrante do LaboMídia/UFSC. Contato: lyanathediga@gmail.com 


\section{Introdução}

A presença ativa das Tecnologias de Informação e Comunicação (TICS) no cotidiano trouxe à tona novas questões sobre a relação das mídias com a Educação Física. Entre elas pode-se destacar a necessidade de formar uma audiência crítica e capaz de interagir com e como produtores das mensagens de forma coerente; de negociar significados, e, mais recentemente, atuar de forma proativa nos chamados "meios colaborativos", veículos que permitem desde a efetiva criação de conteúdos até a pluralização, e pulverização, de ideias e pensamentos.

Imersos nessa nova cultura midiática, para os nativos digitais (PRENSKY, 2001) ${ }^{1}$ esses meios são mais do que simples ferramentas, são espaços de socialização que fazem parte de suas vidas.

Ao afirmar que o meio (canal) pelo qual a comunicação se estabelece, seja ela oral, imagética ou escrita, além de difundir, determina o próprio conteúdo da comunicação, Marshall McLuhan (2006) demonstrou, também, a cultura digital característica do século XXI e vivida atualmente por uma geração que se intercomunica incessantemente, tecendo uma rede de conexões, virtuais e reais, que não apenas faz parte do dia-a-dia, mas que os integra, como extensões do homem.

E nesse contexto, no qual a Educação Física não pode mais ser deixada (ou deixar-se) de fora, Pires (2007) alerta que,

[...] a cultura midiática está intrinsecamente ligada ao cotidiano das infâncias e juventudes, portanto satanizar os meios soa anacrônico para os nossos alunos, além de expressar certo ranço saudosista e conservador. (PIRES, 2007, p. 86)

\section{E sinaliza:}

[...] para proporcionar a apropriação ativa, crítica e criativa, tanto dos instrumentos quanto dos conceitos ligados à mídia, a melhor solução pedagógica parece ser a produção de mídia na escola. (PIRES, 2007, p. 87)

Assim, os novos acessos, bem como as novas linguagens

1 O termo "nativos digitais" é um termo de autoria do escritor Marc Presnky utilizado para designar as primeiras gerações que cresceram cercados pelas tecnologias digitais. Aos que não nasceram sob a égide das tecnologias digitais, o autor denomina Imigrantes Digitais, pessoas capazes de se adaptarem ao ambiente, mas, mantendo um certo "sotaque", ou seja, desnaturalizado. Tal sotaque pode ser percebido de no uso das mídias digitais, uso que para os nativos flui naturalmente enquanto para os imigrantes a utilização será sempre mais difícil, artificial. 
surgidas juntamente com as ferramentas colaborativas que pululam diariamente na web, apontam para uma nova postura do professor de Educação Física na chamada era digital. O foco, que antigamente se concentrava "nos fundamentos técnicos e da prática do jogo, que há anos constituem a centralidade do nosso aprender (na formação acadêmica) e do nosso ensinar (na escola)" (PIRES, 2007, p. 86), hoje se deslocou para um conhecimento mais amplo que envolve conhecer a cultura digital para assim reconhecer como são tematizados os conteúdos que abarcam as práticas corporais e os esportes nesse novo espaço de socialização, refletindo, assim, sobre o papel formador que a Educação Física abona em seus métodos atuais.

Nesse cenário no qual a "onipresença" das mídias digitais, por um lado, facilita e incentiva a participação na elaboração, veiculação e no acesso às informações, por outro dificulta a orientação, o discernimento e a credibilidade em meio a tantos pontos-de-vista, relatamos nossa experiência de produção midiática ocorrida por meio da oficina $A$ incorporação de blogs como ferramenta pedagógica na Educação Física que se propôs como oportunidade de os futuros professores, ou seja, acadêmicos do curso, conhecerem e se apro- priarem de linguagens e formatos utilizados nos blogs, a fim de que esse meio digital passe a ser usado como ferramenta educativa, crítica e pedagógica aproximando as perspectivas entre cultura digital e Educação Física escolar.

No campo teórico, buscamos referências nos estudos em Mídia-educação de Rivoltella (2009; 2010) e Fantin (2010); nos estudos e experiências didático-pedagógicas com mídias realizadas no campo da Educação Física, de Pires (2007) e nos Estudos Culturais com MartinBarbero (1998; 2000).

Assim, acredita-se que essa reflexão possibilitará traçar questionamentos sobre como futuros professores de Educação Física refletem, discutem e tematizam as TICs em suas possíveis atividades escolares, relacionado-as com a (provável) carga educativa, formativa e social que essa prática pode ocasionar.

\section{Mídia-educação (física) e cul- tura digital}

Preocupado em estar cada vez mais presente no contexto no qual estão arraigados os alunos, o contexto midiático, um professor de Educação Física propõe a análise de notícias sobre a Copa do Mundo em jornais e revistas. Como estão posicionadas as matérias? Quais as palavras 
que compõem títulos e linha fina? Qual o tamanho das fotos? Em outra situação, o professor, com o intuito de usar as chamadas "novas mídias", sugere que os alunos construam um blog com as brincadeiras de infância apresentadas nas aulas, no qual deve constar, além de posts regulares, comentários, fotos e até vídeos do You Tube.

Os exemplos acima demonstram um cenário no qual os professores, atentos ao consumo das mídias por seus alunos, lançam mão de diversos recursos midiáticos em suas práticas pedagógicas. E nesse contexto no qual a popularização da internet e das chamadas novas mídias (já nem tão novas assim) é cada vez mais evidente, assim como a oportunidade de (re)produzir conteúdos cada vez mais acessível, a necessidade de discutir as mídias e seus usos tornou-se imprescindível de ser tematizado nas aulas.

Com essa emergência, algumas iniciativas já podem ser observadas nas escolas. Aparelhos de DVD, câmeras filmadoras, computadores com acesso a Internet e todo o tipo de parafernálias digitais podem ser encontradas nos espaços da educação formal, seja devido ao incentivo de programas governamentais como o Programa
Nacional de Informática na Educação (Prolnfo) ${ }^{2}$, que propõe a instalação de laboratórios de informática incentivando o uso pedagógico das tecnologias da informação e comunicação em escolas públicas do ensino básico em todo o país; do projeto Um Computador por Aluno $(\mathrm{UCA})^{3}$, que pretende disponibilizar um computador portátil (laptop) para cada estudante e professor de educação básica em escolas públicas, ou da tentativa do professor em encaixar o conteúdo das aulas e se encaixar no cotidiano dos alunos.

Contudo, a dificuldade que outrora era de acesso às ferramentas, hoje parece ser de apropriação das mesmas pelos professores de Educação Física que, em sua maioria, centram suas atividades no uso instrumental das mídias (lançando mão de vídeos sobre práticas e regras esportivas) seja por falta de uma formação, inicial ou continuada, efetiva que lhes dê subsídios para avançar ou por não estarem sensíveis à necessidade de adequação dos conteúdos a essas novas estruturas nas quais está organizado o mundo digital. Assim, a dificuldade parece ser dupla: além de se adequar a essa nova cultura, o professor terá que adaptar conteúdos, em sua maioria corporais e

2 http://portal.mec.gov.br/index.php?option $=$ com_content\&view $=$ article \&id $=244 \&$ Itemid $=823$

3 http://portal.mec.gov.br/index.php?option $=$ com content \&view $=$ article $\& i d=7609 \&$ catid $=210$ 
esportivos, a esse novo espaço de práticas e de socialização, e, muitas vezes sem saber como fazê-lo.

Com o intuito de auxiliar o professor no emprego das TICs no contexto escolar em sala de aula, a revista Nova Escola ${ }^{4}$ publicou, como matéria de capa intitulada Tecnologia + Conteúdos = Oportunidade de ensino, um painel com dicas e sugestões de como utilizar as ferramentas midiáticas nas disciplinas ministradas no ensino fundamental, considerando que "as novas ferramentas são imprescindíveis para a turma avançar". (NOVA ESCOLA, 2009 , p. 51). Entre os usos, a matéria sugere a criação de blogs, de vídeos, a publicação de textos em comunidades virtuais, entre outros recursos. Mas, para a Educação Física a dica é a utilização de ferramentas que transmitam mensagens nas quais o foco será "o plano de apreciação", aos moldes do paradigma da Teoria Hipodérmica que considera a comunicação dos meios como uma atividade unilateral, um estímulo de um emissor ativo a espera da resposta de um receptor passivo.

O grande recurso tecnológico para as aulas da disciplina
[Educação Física] é mesmo o vídeo, na forma de DVDs ou na internet. Com eles é possível trabalhar as práticas corporais por meio da apreciação. [...] Preparar uma atividade em vídeo sobre o judô, por exemplo, pode servir para explicar as regras que não ficam claras nas transmissões dos jogos olímpicos na TV. (NOVA ESCOLA, 2009, p. 54)

O uso instrumental das mídias na Educação Física, como proposto pela revista da editora Abril, é uma das possibilidades de abordagem das mídias no contexto escolar, e não deve ser a única. Ao centrar-se apenas na dimensão da mídia como um instrumento, lançando mão de vídeos e apresentações em slides como opção didática singular, o professor se fecha às lógicas culturais da sociedade atual. Para Martín-Barbero

Na relação entre Educação e Comunicação, a última quase sempre é reduzida a sua dimensão puramente instrumental. É deixado de fora o que é justamente estratégico pensar: que é a inserção da educação nos complexos processos de comunicação da

4 A revista Nova Escola é uma publicação mensal da Editora Abril. Segmentada para o mercado educacional (professores, diretores e administradores de escolas), possui circulação, auditada pelo Instituto Verificador de Circulação (IVC), de cerca de 450 mil revistas mensais, a maior do gênero segundo o Mídia Dados 2010.

http://midiadados.digitalpages.com.br/home.aspx 
sociedade atual, ou falando de outro modo, pensar no ecossistema comunicativo que constitui o entorno educacional difuso e descentrado em que estamos imersos. Um entorno difuso, pois está composto de uma mescla de linguagens e saberes que circulam por diversos dispositivos mediáticos, mas densa e intrinsecamente interconectados; e descentrados pela relação com os dois centros: escola e livro que a vários séculos organizam o sistema educacional [...] (MARTÍN-BARBERO, 1998 apud SALVATIERRA, S/D, p. 3)

A provocação que o termo ecossistema comunicacional coloca para a educação está na emergência de uma cultura situada em comportamentos sociais e na produção de sentidos, adotando como práticas os novos modos de ver, de interpretar e de apreender. Para Martín-Barbero (2000, p. 55), "a escola deixou de ser o único lugar de legitimação do saber" fazendo com que tal propagação descentralizada transformasse a criança em detentora de saberes diferentes dos saberes do professor. Diversificação e difusão do saber se transformaram em "um dos desafios que o mundo da comunicação apresenta ao sistema educacional". (MARTíN-BARBERO, 2000, p. 55). Opinião compartilhada por
McLuhan que, já no fim da década de 60, previu:

[...] haverá um dia - talvez esse já seja uma realidade - em que as crianças aprenderão muito mais - e muito mais rapidamente - em contato com o mundo exterior do que no recinto escolar. (MCLUHAN, 1969 apud LIMA, 1971, p.7).

Além de não ser mais a Meca do saber, o profeta da Galáxia de Gutenberg observou ainda que "as escolas dispensam, mas e mais, energias diversas preparando escolares para um mundo que já não existe" (MCLUHAN, 1969 apud LIMA, 1971, p.12). Tal reflexão evidenciou que o comportamento da escola não acompanharia, como de fato não acompanhou, as modificações culturais e comunicacionais pelas quais a sociedade tem passado, tornando-se, como de fato tem se tornado "um obstáculo intelectual à progressão acelerada da história" (LIMA, 1971, p.12).

Essa seria a razão vital para que a escola absorva a ideia de um trabalho que contemple uma nova perspectiva da mídia, evitando o fosso entre as experiências midiáticas e culturais dos alunos e de seus professores. O desafio está em como implantar nas aulas e nas práticas, não só do professor 
de Educação Física, bem como na própria escola, uma atmosfera de informação e de conhecimentos múltiplos (MARTÍN-BARBERO, 2000) que observe ao mesmo tempo as experiências culturais heterogêneas e a vertente da informação e comunicação digitais, que se disseminam e se dissipam na velocidade de um clique, por meio de usuários pluriplugados em diversas redes e ao mesmo tempo (Orkut, Facebook, Twitter, blogs, e etc.), multiplicando os espaços para a sociabilidade e a socialização de ideias.

Esse educar, segundo autores da mídia-educação, deve abranger três dimensões: educar com os meios, educar sobre os meios e educar através dos meios, dimensões que podem, e devem, complementar-se entre si. (FANTIN, 2006). Dessa forma, a mídia poderá ser utilizada como instrumento, no auxílio em sala de aula, mas dividirá a utilidade com o uso dos produtos por ela oferecidos que serão analisados de forma a instituir um pensamento crítico e da disseminação dos procedimentos técnicos e produtivos do meio, capacitando o aluno a produzir, de forma ética e com uma estética própria, os produtos midiáticos.

Assim, ao atuarem como canal de circulação do conhecimento e de produção (e reprodução) do consumo cultural em tempo real e ao impelirem os professores que atuem ativamente com/nesses canais, as mídias digitais colocam em xeque um importante papel na construção crítica da cultura digital: a atuação do mediador, nesse caso, do professor. Quais seriam suas capacidades? Como utilizar as mídias na prática pedagógica? $\mathrm{O}$ que compartilhar?

Para tanto, Fantin e Rivoltella (2010) apontam, e propõem, aos professores a necessidade em se adquirir novas potencialidades, capazes de conectá-los às novas lógicas culturais e sociais, ou seja, a esse circuito difuso e descentrado na qual a escola está inserida. E vão buscar em Gardner (2007) as seguintes inteligências como indicação para "uma tarefa da educação para o futuro" (GARDNER, 2007 apud FANTIN; RIVOLTELLA, 2010, p. 102):

- Inteligência disciplinar - conhecer sobre teorias e linguagens da comunicação

- Inteligência sintética - avalizar o que realmente importa em meio a um turbilhão de mensagens, imagens e informações

- Inteligência criativa - subverter as narrativas que estão postas propondo novas formas de agir e pensar

- Inteligência respeitosa - preservar e respeitar a multiculturalidade presente na sociedade

- Inteligência ética - o professor deve agir pautando a verdade 
e o respeito como pertencentes às práticas pedagógicas do professor

Ao desenvolver tais inteligências, o professor estará compassivo à necessidade do uso das mídias, neste caso digitais, como componente das práticas pedagógicas por ele adotadas, encaixando-as, e encaixando-se, nesse ecossistema comunicativo e interativo, uma via de mão dupla à colaboração na construção da cultura digital escolar, incentivada não apenas pelo emissor, mas, sobretudo pelo professor-mediador.

\section{Meios + mensagens + mensa- geiros $=$ blog}

Amparados pelas atuais tecnologias de informação e comunicação (TICs), trocamos o mundo apático, inerte e analógico dos tradicionais meios de comunicação de massa pelas diversas possibilidades de interação comunicacional permitidas pelas recentes ferramentas digitais.
Nessa comunicação de muitos para muitos, no qual produção, bem com veiculação de informações tornou-se algo (quase) coletivo e advindo das mãos mais variadas, os weblogs ${ }^{5}$, ou simplesmente, blogs, se destacam como um agregador de meios, mensageiros e mensagens. Mais de uma década depois de sua criação, tal instrumento subverteu sua função inicial de simples diários pessoais, nos quais o conteúdo era apresentado em cunho íntimo e confessional, para adquirir novas funções, seja como filtro de opiniões e notícias, sistema de "alerta", "controle" e crítica dos meios de comunicação, canal de mobilização e disseminação de informações ou ainda como memória da web, entre outras.

Assim, nesse lugar da rede com características particulares da web 2.0, ${ }^{6}$ nas quais os conteúdos (textos, fotos, arquivos de vídeo, de som, etc.), são postados frequentemente em uma estrutura pré-determinada, regular e gratuita onde estão

5 O termo "blog" é uma contração da expressão inglesa web e log, que significa, em tradução livre, registro na internet. Foi utilizado pela primeira vez em 1997 por Jorn Barger criador do pioneiro blog, o Robot Wisdon (AMARAL; RECUERO; MONTARDO, 2009).

6 Considerada a segunda geração de serviços da web, por meio dela foram disponibilizadas ferramentas que possibilitam troca de informações e colaboração dos internautas com sites e serviços virtuais, na organização do conteúdo (wikis, blogs, rss, tags, adsense, etc.), de forma fácil e barata. Contudo, para alguns analistas da internet o universo digital sempre apresentou possibilidades para a interatividade como é realizada hoje, fazendo dessa característica um movimento natural e, por isso, tal fato não justificaria o título de "a segunda geração". Cabe ressaltar que, por se tratar de uma área em constante mutação, tal definição não se pretende definitiva ou estanque admitindo, e incentivando, novas interpretações e entendimentos. 
presentes links que o ligam a outros conteúdos de seu interesse (sites, blogs, scribd, wiki, repositórios, etc) e posicionados em ordem cronológica inversa possibilitando aos leitores a opção de comentar em qualquer postagem individual, a participação, colaboração, o diálogo com múltiplas comunidades, a interatividade , a mobilidade fazem desse espaço um importante meio para

[...] produção dos saberes e [...] para um ensino interdisciplinar e participativo, construído por ações colaborativas entre todos os responsáveis em promover a formação educacional das crianças e adolescentes (BIANCHI, 2009, p. 228).

Ao tecer redes e confeccionar grupos ligados por interesses em comum, os blogs se assumiram como espaços dedicados a observação de objetos determinados, direcionados a um público específico e, consequentemente, atraindo a atenção desse público em uma via de mão dupla que permite ao receptor interagir com o emissor, bem como o receptor ser o emissor constituindo-se como um leitor-autor, em qualquer lugar e a qualquer hora. Desta forma, se constituem, cada vez mais, como veículos privilegiados na difusão de informação e conhecimento sobre um assunto, entre eles, conteúdos que tematizam os objetos da Educação Física. Esse novo movimento comunicacional promoveu novas formas, não apenas de socialização, mas de consumo das informações, que se dá em um movimento frenético, plural e, até mesmo, vertiginoso.

Entendido como meio que possibilita a convergência de formatos em uma mesma mensagem - um post pode ser "escrito" com um texto e exemplificado com um vídeo, ou pode apresentar um arquivo de voz e uma fotografia, entre tantos outros usos -, os blogs são hoje um exemplo de um sistema de comunicação característica da sociedade multitela na qual

A lógica comunicativa do tipo um-a-muitos, que no tempo da televisão generalista configurava a condição do espectador como de um terminal mais ou menos passivo do sistema de comunicação, é substituída por uma lógica de comunicação muitos-a-muitos, com forte estrutura interativa em que o espectador se transforma em usuário de serviços (FANTIN; RIVOLTELLA, 2010. p. 91)

Em uma sociedade multitela, a comunicação e os meios de massa cada vez mais ruem tal castelo de areia, fragmentando, 
descentralizando e pulverizando informações ao vento, ou melhor, pelo espaço insurgente e sem fim da internet. E nesse ambiente, cada grão tem a possibilidade de se estabelecer e colocar o seu pensamento livremente, por meio de ferramentas gratuitas e intuitivas, como o blog.

\section{Narrando e vivendo uma ex- periência}

Constituir afinidades entre diversos campos do conhecimento, estabelecendo uma relação dialógica entre eles, é uma prática tanto imperativa quanto recorrente nos dias de hoje em que a comunicação ocorre por canais que confluem, convergem e, muitas vezes, confundem o acesso à informação. Assim como acontece com a mensagem informativa, também a educativa, posto que talvez elas não se separem, são instâncias criadoras e transformadoras da realidade, na qual o professor deve estar inserido.

A experiência e formação na área da publicidade e jornalismo e o recente contato/ convívio com a Educação Física, possibilitou a observação das práticas que pautam a cultura e a inserção das plataformas digitais na formação acadêmica, e a dificuldade em se constituir novas relações entre os conteúdos da Educação Física com a cultura digital. Tal observação, que ainda se situa mais fora do que dentro do sistema escolar assim como ocorreu com McLuhan ${ }^{7}$, tornou-se terreno fértil para a formulação da proposta de uma oficina de blogs para os acadêmicos e para o cultivo de mais questões acerca do tema.

Assim, foi pensada a realização de oficinas cujo objetivo inicial foi demonstrar como os blogs funcionam, tematizando algumas ferramentas e comportamentos que os compõem e que, de forma geral, constituem a cultura digital na qual estamos imersos, amparando na formação do futuro professor como um mediador capaz de auxiliar os alunos a se apropriarem de forma crítica e inventiva das mídias digitais, ou seja, a atuar como um mídia-educador.

A escolha dos blogs se deu pela possibilidade que a ferramenta abona de proporcionar interatividade, a troca de informações e a colaboração dos internautas e pelo agrupamento de mídias em um mesmo

7 Foi no Centre for Culture and Technology, na Universidade de Toronto, que o pesquisador Herbert Marshall McLuhan, conhecido como "papa da comunicação", se constituiu como expoente nos estudos sobre comunicação e tecnologia. Assim, "de fora do sistema escolar, McLuhan foi capaz de realizar todas as previsões que os educadores mais ousados vinham fazendo com relação ao destino prospectivo da instituição escolar." (LIMA, 1971, p.5). 
espaço, características inerentes à web 2.0, relações dadas por meio de um simples acesso, gratuito, de manejo fácil e intuitivo.

A ementa e a programação da oficina sugeriram: i) Ementa: introdução às características da mídia blog observando como ela se insere na cultura digital e seu potencial pedagógico como espaço produção, permuta e armazenamento de informação especializada, ii) Programa: distribuição de informações, interatividade e linguagem; não-linearidade; convergência entre as mídias; estruturação e tipos de conteúdos; hipertexto e hipermídia; autoria na internet - noções de copyright e copyleft (creative commons); instrumentos de busca, análise e agregadores e disseminadores de conteúdos (analytics, delicius, flickr, youtube, myspace, twitter, etc); criação e edição de blog coletivo (blogspot).

A primeira oficina ministrada foi oferecida aos acadêmicos do curso de licenciatura em Educação no Campo da Universidade Federal de Santa Catarina (UFSC) e serviu como piloto para a prática das demais. Em apenas um encontro de duas horas, o foco fixou-se na construção coletiva de um blog que abarcasse toda a turma e que servisse como efetiva ferramenta de comunicação capaz de agregar a turma, servir como repositório, fórum de debates e "vitrine" para os demais cursos e interessados em educação no campo. ${ }^{8}$ Nesse primeiro contato foi possível estabelecer algumas necessidades tais como, o aprofundamento em questões estruturais e de autoria, que foram melhor tematizadas nos demais encontros.

As oficinas oferecidas para acadêmicos do curso de Educação Física aconteceram em duas instituições e em momentos distintos: i) acadêmicos (licenciatura e bacharelado) da Universidade Federal de Santa Catarina (UFSC) durante a XI Semana de Educação Física (XI SEF), realizada de 24 a 28/05 de 2010 e em um encontro com os participante da disciplina de Educação Física e Mídia ${ }^{9}$ oferecida no primeiro semestre de 2010, e ii) acadêmicos (licenciatura e bacharelado), da

8 Cabe ressaltar que a formação de educadores conscientes para os usos das mídias é uma das preocupações da licenciatura em Educação no Campo da UFSC, sendo a temática tratada de forma transversal, ou seja, atravessando todos os conteúdos do curso. O blog construído durante a oficina é periodicamente atualizado pelos acadêmicos do curso, que o utilizam das mais diversas formas. O blog pode ser acessado pelo seguinte endereço: http://www.educampoufsc.blogspot.com/

9 Educação Física e Mídia é uma disciplina optativa oferecida aos acadêmicos de Educação Física da UFSC. É ministrada por seu idealizador, o prof. Dr. Giovani De Lorenzi Pires. O professor ainda oferece, regularmente, no Programa de Pós Graduação em Educação Física (PPGEF) disciplina equivalente à acima citada. 
Universidade Federal de Sergipe (UFS), por ocasião do II Encontro Nacional de Observatórios da Mídia Esportiva, ocorrido nos dias 14 e 14/10 do mesmo ano. Porém, todos as oficinas foram ministradas em um único encontro.

Para os acadêmicos da UFSC que participaram da oficina oferecida na XI SEF, optou-se pelo oferecimento de apenas oito vagas devido ao espaço físico que limitou a oferta, todas preenchidas por alunas do curso. O período pré-estabelecido foi de 4 horas, tempo suficiente para a explanação de todos os pontos propostos. No encontro durante a disciplina de Educação Física e Mídia, o tempo foi reduzido para apenas duas horas.

Os alunos sergipanos também contaram com apenas duas horas de oficina, da qual participaram cerca de 20 alunos. Para eles, optou-se por uma explanação realizada juntamente com a construção propriamente dita de um blog, uma vez que o tempo escasso não possibilitaria a imersão teórica que foi satisfatoriamente inserida na prática, ou seja, na criação conjunta do blog.

$\mathrm{Na}$ oficina realizada na UFSC optou-se, na primeira parte, por uma apresentação de slides. Contudo, em ambas foi priorizada a conversa sobre as experiências no uso das ferramentas e a inserção na cultura digital, possibilitando uma maior interação e observação acerca da (possível) complexidade que o assunto abordado poderia suscitar nos alunos.

As reações observadas em ambos os grupos foram praticamente as mesmas: a de que os alunos não parecem estar envolvidos ou talvez, não consigam fazer relação entre os conteúdos da Educação Física com a cultura digital, ou, ainda, não conhecem as ferramentas que constituem tal ambiente.

Ciente dessa (possível) dificuldade, uma vez que ela se reflete em diversos âmbitos dentro do curso, priorizou-se tanto a demonstração de exemplos práticos da presença da Educação Física nesses espaços com dicas de atuação, como a criação em conjunto, negociando com os participantes decisões como título, tema, endereço e layout do blog, entre outros, construindo juntos, assim como pode ser feito em sala de aula.

As questões sobre o acesso e a reprodução das informações e dos conhecimentos e provocações sobre o conceito de espaço público e privado dentro das mídias digitais, foram presença constante e permearam todos os pontos tematizados e trabalhados pelas oficinas.

Entre tantos conceitos e conteúdos, aparentemente novos, os futuros professores puderam observar que as mídias digitais são 
mais que ferramentas e fazem parte não só da vida dos alunos, mas da vida de todos, nossas próprias vidas.

\section{Conclusões}

Oferecer uma oficina aplicada aos docentes, neste caso futuros professores, forneceu novos pontos para a observação da relação Educação Física e cultura digital. Foi possível observar, por exemplo, como os acadêmicos percebem a inserção dos meios digitais atrelados aos conteúdos propostos; se os blogs são reconhecidos como potenciais espaços para a construção e disseminação do conhecimento e, como se dá a relação deles com tais ferramentas, instrumentos que, mesmo presentes no cotidiano, não parecem subverter o plano do entretenimento e da baixa participação.

O curioso foi constatar que, mesmo cercados pela presença e pela apropriação de todo o tipo de engenhocas digitais presentes em nosso dia-a-dia, de computadores a mp3, passando por máquinas de lavar e caixas eletrônicos, contato que muitos dos participantes possuem desde o nascimento, resultado que, segundo Prensky (2001) encaixaria tais acadêmicos no grupo de nativos digitais, habituados em "receber informações muito rapidamente; processar mais de uma coisa por vez, realizar múltiplas tarefas [e] trabalhar melhor quando ligados a uma rede de contatos" (2001, p. 2), há uma clara dificuldade dos acadêmicos em perceberem como as ferramentas da web 2.0, bem como as próprias TICs, podem ser inseridas nos contexto escolares, de forma a ultrapassar a barreira da contemplação. Essa concepção pode ser advinda do próprio entendimento que os acadêmicos possuem da escola: um lugar no qual os usos das TICs devem ser formatados em um "pedagogismo" maçante e retrógrado, que desestimula e, ao que parece, bloqueia qualquer iniciativa de inclusão.

Contudo, ao oferecer uma oficina como a de blogs, o objetivo não seria, de fato, a adesão instantânea à ferramenta, mas uma sensibilização para a importância de se inserir, ou pelo menos perceber, o que ocorre dentro desse "ecossistema comunicativo" do qual os professores, ainda, não fazem parte. Porém, a oficina se dedica a acadêmicos, que, de certa forma, estão inseridos nessa cultura digital. Nesse caso, a sensibilização não deveria ocorrer com mais facilidade?

Desta forma, pode-se ponderar que a inovação no contexto escolar independe do grau de uso privado das tecnologias digitais ou da disponibilidade de acesso às ferramentas. O que leva à observação a uma outra questão: a forma como 
a escola está disposta a receber e a promover tais usos dentro do seu território, no qual

\begin{abstract}
A educação escolar tradicional dispõe de impressionante acervo de meios próprios para suscitar em nós o desgosto por seja qual for a atividade humana, por mais atraente que seja na partida (MCLUHAN, 1969 apud LIMA, 1971, p.33).
\end{abstract}

O papa da comunicação, mais uma vez, parece ter previsto uma situação na qual a escola e os professores estão, há muito, inseridos. Voltamos ao ponto de partida?

\section{Referências}

BIANCHI, Paula. Relato de experiência em mídia-educação (física) com professores da rede municipal de ensino de Florianópolis/sc. In Pires, Giovani; Dorenski, Sérgio (orgs). Pesquisa em educação física e mídia: contribuições do Labomídia/ UFSC. Florianópolis: Tribo da Ilha, 2009

FANTIN, Mônica. Mídia-educação: conceitos, experiências, diálogos Brasil-Itália. Cidade Futura: Florianópolis, 2006.

FANTIN, Mônica; RIVOLTELLA, Pier Cesare. Crianças na era digital: desafios da comunicação e da educação. REU, Sorocaba, SP, v. 36 , n.1, p. 89-104, jun. 2010

ILHARCO, Fernando. Sobre McLuhan. Figuras da Modernidade: McLuhan. Conhecer a FCH - Conferências Multidisciplinares. Universidade Católica Portuguesa (UCP). Lisboa, 2005. Acesso em 20. out. 2010 Disponível em <http:// www.ucp.pt/site/resources/ documents/FCH/F\% 20llharco/ FIGURA \% 20 m cluhan $\% 20$ FINAL.pdf >

LIMA, Lauro de Oliveira. Mutações em educação segundo McLuhan. $2^{\text {a }}$ ed. Vozes: Petrópolis, 1971.

MARTÍN-BARBERO, Jesús. Desafios culturais da comunicação à educação. Revista Comunicação e Educação. São Paulo, n. 18, maio./ago, 2000. p. 51-61

MARTÍN-BARBERO, Jesús. Dos meios às mediações: comunicação, cultura e hegemonia. Tradução Ronald Polito; Sérgio Alcides. 2 ed. Rio de Janeiro: UFRJ, 2001.

MCLUHAN, Marshall. Os meios de comunicação como extensão do homem. 18 ed. Cultrix: São Paulo, 2006.

PIRES, Giovani De Lorenzi. Oesportee os meios decomunicaçãode massa: relações de parceria e tensão possibilidades de superação. In, GRUNENNVALDT, José Tarcísio 
et al. (orgs). Educação Física, esporte e sociedade: temas emergentes. São Cristóvão: DEF/ UFS, 2007.

PRENSKY, Marc. Nativos Digitais, Imigrantes Digitais. NCB University Press, Vol. 9 No. 5, Outubro 2001. Acesso em 7. out. 2010 Disponível em: <http://api.ning.com/ files/EbPsZU1BsEN0i*42tYnd650YRCrrtli8XBkX3j8*2s_I Texto_1_Nativos_Digitais_ Imigrantes_Digitais.pdf $>$
REVISTA NOVA ESCOLA, São Paulo: Editora Abril. N, 223, jun. jul/2009.

SALVATIERRA, Eliany. Ecossistema Cognitivo e Comunicativo. Acesso em 7. out. 2010 Disponível em < http://www.usp.br/nce/ aeducomunicacao/saibamais/ textos/>

Recebido: outubro/2010 Aprovado: novembro/2010 